\title{
Exploring Benefit Transfer: Disamenities of Waste Transfer Stations
}

\author{
TZIPI ESHET ${ }^{1, *}$, MIRA G. BARON ${ }^{2,}$ and MORDECHAI SHECHTER ${ }^{3}$, \\ ${ }^{1}$ Faculty of Civil and Environmental Engineering, Technion, Haifa, 32000, Israel; ${ }^{2}$ Faculty of \\ Industrial Engineering \& Management, Technion, Haifa, Israel; ${ }^{3}$ Natural Resource and \\ Environmental Research Center, University of Haifa, Haifa, Israel; *Author for correspondence \\ (E-mail:eshet@techunix.technion.ac.il)
}

Accepted 28 September 2006

\begin{abstract}
The benefit transfer method was developed as an alternative way to value externalities using values from studies of similar circumstances, carried out at similar sites somewhere else, given the challenges and high costs inherent in assessing the actual cost. Specifically, in order to test the performance of the benefit transfer method, employing hedonic price models, this study focused on estimates of disamenities associated with waste transfer stations at four different cities in Israel. The sites were intentionally selected to represent a variety of circumstances. We transferred the estimated benefit function from a "study site" to a "policy site". The goodness of fit was examined by comparing the calculated value, with actual data from the policy site. To test the sensitivity of the benefit transfer function to socioeconomic and housing characteristics, it was repeatedly applied to different sets of observations. The findings suggest that a relatively large number of alternative benefit functions are transferable. Statistical inequality outcome regarding the degree of similarity between samples does not unequivocally rule out the appropriateness of transferring environmental values across studies. Transfer errors varied between $-21 \%$ and $+29 \%$, and the absolute average error for all transfers was $15.4 \%$. Errors were lower for transfer between relatively similar cities in terms of size and location and between sub-samples that were similar in socioeconomic characteristics and housing type. However, when a site with very dissimilar data was involved, the average absolute error rose to $19 \%$.
\end{abstract}

Key words: benefit transfer, disamenity, hedonic pricing, valuation, waste management, waste transfer stations

\section{Introduction}

Various methods and techniques have been developed in the field of environmental economics to measure the value that people attach to non-market environmental-attributes. Estimating the values in monetary terms is feasible through the concept of an individual's Willingness To Pay (WTP). The WTP for use and non-use values can be measured directly through stated preference (SP) methods (e.g., contingent valuation - CV) and indirectly by assuming that the environmental use value is revealed in the related costs of 
commodities in the market, such as travel cost (TC) to a specific recreation site or prices paid to live in a specific location through the hedonic pricing method (HPM) (Brouwer 2000). A variety of studies have been conducted worldwide using the above methods, yielding a published list of monetary valuations concerning diverse environmental issues (e.g., the Environmental Valuation Reference Inventory (EVRI), which is a database of valuation studies accessible through Internet). The question that has been the focus of attention for researchers and decision makers (and is the core of our study) regards the feasibility of using these valuations for further applications with sufficient accuracy. In other words, the issue is whether preferences estimated from a study site could be transferred to a policy site to predict the behavior of the residents there (Bateman et al. 2002; Hanley et al. 2006).

The process of transferring existing economic valuations of non-market environmental goods or impacts (benefit or damage) from one site (study site) to a new different study (policy site) through economic valuation techniques is called the Benefit Transfer (BT) method (also discussed as "environmental value transfer" (Barton 2002) and "Plug-in values" (Boardman et al. 2001)). In essence, this involves using existing data to make predictions in a new policy subject in a cost-effective way (Boyle and Bergstrom 1992; Brouwer 2000; Oglethorpe et al. 2000). The transfer can be conducted between sites in the same country as well as between different countries, although the later raises among others, the issue of the monetary units.

Among existing environmental studies, only a limited number of valuation studies of environmental damage and disamenity have been undertaken for the waste sector, and therefore there are no monetary valuations for all impacts from waste sites such as landfills and transfer stations. Thus, the BT method may offer an efficient device to extend the economic valuation of externalities from waste facilities, although there is as yet no consensus on the reliability of BT experiments across contexts.

A basic objective of our study was to enrich the understanding and knowledge about the usefulness, feasibility, and limitations of using the BT method in the waste sector and to provide further empirical evidence for the validity of BT through HPM studies, particularly as the topic of the performance of BT with hedonic studies has not yet been examined sufficiently.

The principle hypothesis of the study was that monetary estimates for an environmental attribute derived in one location (in Israel) for one type of policy decision could legitimately be employed in other decision-making practices. Specifically, the study examined whether benefit transfers may be legitimate in the context of applying disamenity valuations associated with a transfer station at one location to decisions made regarding transfer stations at other locations. The case study involves four transfer stations in Israel. The examination was based on data and results from a comprehensive HPM 
valuation study we had recently carried out that estimated the impacts of disamenities associated with transfer stations, on property values, in four cities in Israel (Eshet et al. 2006). That HPM study seemed a priori appropriate for BT exercises as it fits the basic criteria for successful BT, including an identical survey instrument to evaluate the same good in all compared sites and adequate data in the analysis as well as the same statistical techniques. The sites were specifically chosen to represent a mix of similar and dissimilar samples, allowing us to assess the performance of BT among similar as well as different sites and to analyze where BT may or may not work effectively. The chosen sites included similar populations who faced fairly similar environmental conditions. Three of the cities were more similar to one another, and one was different with respect to location and population, as well as the availability of data. An additional essential study hypothesis was that if there were substantial difficulties in explaining variations in the values found then it would be difficult to legitimize the use of BT in this context. Thus, the present study involved some statistically controlled experiments to examine those hypotheses in reference to the variability in the characteristics of the sites and populations. The results of this study will be useful to waste managers and policy makers in their modus operandi as well as to environmental-economic researchers who consistently look for new evidence on the functioning of BT.

\section{Benefit Transfer Method}

\subsection{USING BENEFIT TRANSFER}

Conducting original valuation research for each specific policy action is usually advisable because of its higher accuracy. However, because valuation of externalities is always difficult and sometimes even not feasible, and because implementation of valuation methods is usually pricey and timeconsuming, the benefit transfer method was developed as an alternative way to value externalities, given the challenges inherent in determining their actual cost, enabling the use of welfare estimates from existing studies in the evaluation of new policies. The use of BT as an alternative valuation method has some advantages. From a practical perspective BT has the advantage of reducing both time and financial resources that are needed to develop separate evaluations for each individual policy decision. From a methodological viewpoint, BT may provide a degree of consistency in decision-making through the use of common parameters across studies (Johnson and Button 1997; EC 2000; Jiang et al. 2005).

Despite its potential drawbacks involving a risk of biased estimates, BT is now generally accepted as an appropriate method for valuation, particularly when the degree of accuracy does not have to be high, as in cases of initial 
screening of projects, establishing limits within which parameters may lie, and when a large number of relatively standard but linked policy issues are being addressed (EC 2000). Oglethorpe et al. (2000) add that the marginal savings by not carrying out surveys at all may be relatively greater than the marginal increase in error created through BT. Certain strict conditions and criteria have to be met, however, for a valid BT process. First of all, the quality of the potential study site values is critical to the quality of BT because if original-study results are questionable in terms of validity and reliability, their use in new policy contexts will only result in more controversy (Boyle and Bergstrom 1992; Brouwer 2000). The original values must be examined to determine whether they are sound and adequate for transfer in terms of data collection procedures, statistical methods, and the nonmarket valuation application itself. Then, transferability needs to be evaluated for both study and policy sites, using objective criteria and checking for equality or at least great similarity at both the study and policy sites, regarding the environmental attribute valued, population affected, and site characteristics (ODPM 2002; Boyle and Bergstrom 1992). Note that although the BT method is based on a strong hypothesis that the study site and the policy site are perfect substitutes, practically, "sufficiently similar" sites are acceptable (Rozan 2004).

\subsection{TRANSFER APPROACHES}

Three broad approaches are in use for BT: transferring mean unit values, transferring benefit functions, and transferring meta-analysis functions.

\subsubsection{Mean unit value transfer (UVT)}

In this basic procedure a mean value of WTP from a study site is directly applied to a policy site. The transfer is relatively simple when the sites are located in the same country and are similar in all characteristics so that the mean WTP from the study site can just be multiplied by the affected population size at the policy site. When a mean WTP is transferred from a site in one country to a policy site in another country, however, some questions arise, besides the correcting for income differentials, about factors that are not taken into consideration in this approach, such as the influence of geographical, cultural, socioeconomic, and political differences on the WTP. Thus, the advantage of this approach lies in its simplicity, but the results are not precise (Rozan 2004). Some improvement of this approach can be achieved by adjusting the mean values before the transfer, in terms of the differences between sites and populations. There are some techniques for adjustments (Bateman et al. 2002): assuming that income is the most 
important factor that influences WTP, adjustment of income differences is widely used, especially for transfers between countries, according to the following formula:

$$
\mathrm{WTP}_{p}=\mathrm{WTP}_{s}\left(Y_{p} / Y_{s}\right)^{e}
$$

where $p$ is a character for the policy site and $s$ for the study site, $Y$ is income per capita and $e$ is the income elasticity of WTP. (This kind of adjustment has been widely employed in benefit transfers from the USA to Europe (e.g., Krupnick et al. 1996).) Other common adjustments are employed for population size and for the distribution of population characteristics.

\subsubsection{Benefit function transfer (BFT)}

This approach, which involves transferring an estimated benefit function from a study site to a policy site, is more sophisticated and is assumed to produce more accurate results than the above approach mainly because it transfers more information. The concept is that if a benefit function at a study site is given $\left(\mathrm{WTP}_{s}\right)$, then it is possible to predict $\mathrm{WTP}_{p}$ for a similar policy site. In other words, a single BFT uses the coefficients from a selected study site combined with values of explanatory variables of the policy site; meaning that only the relationship from the study site is transferred while data from the policy site is applied to the relationship (Bateman et al. 2002; EC 2000). The transfer can be drawn as in the following linear model:

$$
\begin{aligned}
\text { Predicted } \operatorname{WTP}_{p}= & f\left(\beta_{s}, X_{p}\right)=\beta_{s_{0}}+\beta_{s_{1}} \cdot X_{p_{1}}+\beta_{s_{2}} \cdot X_{p_{2}} \\
& +\beta_{s_{3}} \cdot X_{p_{3}}+\beta_{s_{4}} \cdot X_{p_{4}} \cdots \beta_{s_{n}} \cdot X_{p_{n}}
\end{aligned}
$$

where $\beta_{s_{1}} \cdots \beta_{s_{n}}$ are parameters (coefficients) that have been estimated at the study site and $X_{p_{1}} \cdots X_{p_{n}}$ are the explanatory variables at the policy site, including, for example, characteristics of the environmental attribute of interest and the site itself as well as socioeconomic characteristics. Certainly, the hypothesis for this procedure is that the explanatory variables of WTP are of the same categories in the two sites (Rozan 2004).

\subsubsection{Meta-analysis functions transfer (MFT)}

Meta-analysis is commonly defined as a statistical analysis of the summary findings of past empirical studies that deal with the same subject. The most common use of meta-analysis has been to analyze the variations in welfare measures due to differences in methodological assumptions of valuation studies. Meta-analysis treats each study as one observation. It attempts to identify causal relationships between explanatory variables and benefit estimates and looks for study characteristics as potential explanations for 
consistent results across studies in order to arrive at useful generalizations (Brouwer et al. 1999; Oglethorpe et al. 2000). Using this most advanced alternative to predict values at a new policy site using site-specific variables (named "meta-benefit function transfer" by Barton (2002)), WTP functions do not come from a single study but from a collection of studies. The form that meta-regression analysis takes is as follows (Johnson and Button 1997):

$$
\mathrm{WTP}_{j}=\beta+\sum \alpha_{k} Z_{j k}+u_{j} \quad(j=1,2, \ldots J)(k=1,2, \ldots \ldots K)
$$

where $j$ is the index of the study from a total of $J$ studies; $k$ is the index of the characteristic from a total of $K$ characteristics that are controlled; $\alpha_{k}$ are the coefficients of the $K$ characteristics; $\beta$ is the summary value of WTP; $Z_{j k}$ are characteristic variables of a study that could explain variations amongst studies and $u_{j}$ is the error term. Explaining the variations in WTP reveals what WTP depends on and thus improves the transfer of values. Generally, uncertainty decreases and accuracy increases with increasing information about the policy site and as the number of the included studies increases.

\subsection{TESTS OF TRANSFERABILITY}

Appropriateness of the BT process implies that either some common parameters are applicable to all studies or at least one can explain variations between studies so that parameters taken from one context can adequately be modified for use in a second context (Johnson and Button 1997). Generally, applicability of the principle of BT is based on the extent to which data from different samples can be pooled (Hanley et al. 2006). The validity tests are based on the general premise that an effective transfer largely depends on the degree of similarity between the study sites and the policy site with respect to factors including geographic location, type and level of amenity, and the cultural and socioeconomic profile of the population. Similarity is a necessary condition but not a sufficient condition, however (Chattopadhyay 2003).

A simple way (but not economically recommended) to test the reliability of BT could be by predicting WTP based on primary studies, before an actual project is implemented and then revisiting the area when the project is completed to observe whether people behave according to their expected WTP. However, Researchers aimed to develop a more sophisticated (and cheaper) scheme to test the soundness of BT practice; though, the exercises might require making a large number of a priori assumptions about the environmental conditions at the sites, the affected population, etc.

Basic transferability tests that examine the data from different samples, involve taking actual WTP functions from different studies (two or more) and checking whether they are statistically equivalent and will produce similar benefit estimates $\left(\mathrm{WTP}_{s}=\mathrm{WTP}_{p}\right)($ Pearce and Howarth 2000). Downing and 
Ozuna (1996) state that BFT is possible only when the estimated coefficients of two samples are statistically equivalent. There are several acknowledged and classical statistical methods that can fulfill the task of equality tests, such as the Wald and Chow tests (see Section 5.1). Kristofersson and Navrud (2005) recommend considering equivalency tests as alternative or additional tests for the validity of environmental BT. As opposed to equality tests, the null hypothesis of an equivalency test is that the values are different (actually within an interval), and only through rejection of the null hypothesis can one conclude that the values are equivalent. Muthke and Holm-Mueller (2004) deals also with the same issue regarding the null hypothesis of different WTP.

At the final stage of a BT exercise via one of the transfer approaches, the deviation of the transferred result from the "true" model estimate can be calculated. The transfer-error rate (TER) was defined by Ready et al. (2004) and Rozan (2004) as the absolute percent difference between a transferred estimate of WTP and the estimate obtained originally in the target site itself.

\subsection{TRANSFERRING APPROACHES - LITERATURE REVIEW}

Some empirical studies have looked into the issue of the preferred approach for BT. Kirchhoff et al. (1997) performed CV mail-surveys to estimate the preferences regarding some river recreation activities (similar but not identical) in four sites in the USA among visitors who do not reside in the locality of the sites. They tested the performance of both UVT and BFT between pairs of sites. They argued that the BFT was found to be more robust than the transfer of mean values. However, the authors concluded that the transfer errors (2-228\% in this case) occurring in the application of both BT methods can be large even across seemingly similar amenities. In another study, Kirchhoff (1998) provided, through a comprehensive survey of recreational valuation-studies, an additional perspective on transfers. He argued that although a meta-analysis method is preferred for BT because it supplies estimates from a number of similar studies, he showed that transfers based on meta-analysis generally lead to greater errors than those of BFT when no site-specific variables were included. When meta-analyses included significant site quality, substitute and socioeconomic variables, however, BFT did not clearly outperform them. Brouwer and Spaninks (1999) estimated the WTP for conservation of peat meadowlands at two sites in the Netherlands (slightly different good with similar populations). They found that although the transfer of values based on value functions was not valid in all cases, it outperformed transfer of unadjusted average unit values (error of $27-36 \%$ for unit value transfer and $22 \%$ for function transfer). They also showed that equality of the coefficient estimates is a necessary but not a sufficient condition for valid BFT. These results contrast with those of Ready et al. (2004), 
who measured (via CV surveys) identically described goods (air and water quality) with different populations (in five European countries). They tested the three transfer methods and concluded that there were few differences among their performance, with an average transfer error of $38 \%$. Thus, contrary to expectation, the use of BFT instead of adjustment of UVT for income differences did not improve the performance of the transfer. Navrud (2001) conducted a CV study to estimate health impacts from air pollution in Norway. Afterwards, he compared the WTP results of his study to estimates of the same health damage that were transferred from USA only by adjusting the mean values with the consumer price index. The comparison suggested that this transfer approach led to highly biased values in the Norwegian case, as the transferred estimates significantly overstate the original WTP derived in Norway; thus, BT was not justified in that case. The author concluded that the divergences might be related to differences in: the CV surveys, preferences in both countries, and the public health care system. However, he did not employ other transfer approaches for additional comparison of results. Adversatively, Alberini et al. (1995), who also transferred estimates from the USA to Taiwan on health impacts from air pollution, justified the transfer of simple adjusted mean values, because the results were statistically the same for both countries. Average transfer errors ranged from $29 \%$ to $54 \%$. Finally, Brouwer and Bateman (2005) tested BT of WTP estimates and functions for health risks associated with solar ultraviolet exposure, in four countries. From the transfer error calculations, it became clear that when transferring between similar countries (i.e., regarding population characteristics), simple UVT (0.4\% transfer error) outperforms BFT (18.7\% transfer error). This result is reversed, however, when transfers were conducted across dissimilar countries where errors generated by UVT (30.7\%) were considerably larger than those arising from BFT $(9 \%)$.

Most studies suggest that transferring functions is better than transferring average values. Generally, however, regardless of the kind of the transfer approach, the BT method has been found to work better in some contexts than others. Besides methodological differences, this may be attributed especially to differences in socioeconomic characteristics.

\section{Hedonic Price Method (HPM)}

The issue of applying BT to HPM studies has not been sufficiently investigated. HPM studies aim to place indirect monetary values on externalities resulting from disamenities by examining the impact on property values in residential areas adjacent to undesirable land uses, such as waste transfer stations. They look at marginal changes in real estate values associated with additional units of disamenity, which is commonly measured by the distance 
from a property to the nuisance site (Cambridge Econometrics et al. 2003; Shechter 1995; ODPM 2002). Decreased property values are a societal cost or externality, because the loss is not borne by the owners of the impact producing facility itself. It is borne by the property owners and by society in general (Beloff et al. 2000). Generally, under competitive conditions, a hedonic equilibrium requires that the change in any attribute (at a given level of the other attributes) yield the marginal bid and marginal offer of the buyers and sellers for that characteristic. Thus the hedonic price function (HPF) "defines" the market equilibrium, and its slope with respect to each characteristic provides an estimate of residents' marginal WTP for changes in that attribute (Smith and Huang 1995).

Comparison of hedonic pricing (HP) and stated preferences (SP) studies shows that HPM surveys are more uniformly applied than CVM, and it is also usually clearer in HPM what is measured, that is a use-value revealed through the price people actually paid to enjoy an environmental attribute. Nonetheless, HP studies could also suffer from some flaws associated with assumptions made by researchers about the housing and environmental preferences. So people's perceptions and valuation of these characteristics may differ from the characteristics as identified by the researchers and hence remain outside the scope of the model. This may also influence the effectiveness of transferring these characteristics across sites (Brouwer 2000). A meta-analysis of HPM studies can provide a statistical synthesis of empirical studies focused on a common hypothesis or model. Most such analyses have summarized effect sizes or evaluated the evidence from test results across a variety of different types of experiments (Smith and Huang 1995).

\subsection{A REVIEW OF HPM STUDIES APPLYING BENEFIT TRANSFER}

In practice, BT applications can rely on estimates based on revealed behavior as well as estimates based on SP elicitation mechanisms. The vast majority of studies in the literature associated with BT investigated the functionality of BT through SP methods and only a few studies have tested the validity of transferring HPM valuations, most likely because the latter involves a possible problem of segmented markets and also seems to be more difficult to attain. To our knowledge, our study is the first to examine BT performance on a pre-designed HPM study in the context of waste management. In the following, a short review of such HPM studies; note that only the first two studies are associated with waste management context and only Chattopadhyay (2003) was originally designed for BT exercises.

Brisson and Pearce (1995) estimated disamenities costs associated with incinerators and landfills in the UK. In the absence of original studies in 
Europe at that time, they "borrowed" and investigated results from eleven HP studies and three CV studies that had been carried out in the USA in order to adjust them to the UK at least for a preliminary estimate. A "metafunction" from HP studies appeared to be consistent with the results of the BT from the CV studies. The authors suggested a general formula for adjusted BT that accounted for income levels and elasticity of income in both study and policy sites, but, they did not discuss in this paper the limits, reliability, and feasibility of the BT process they performed. Cambridge Econometrics et al. (2003) conducted a primary comprehensive hedonic study to estimate the economic value of disamenities associated with landfills in the UK. A combined database identified 11,300 landfills that were associated with 592,000 housing transactions between 1991 and 2000. They argued that because the implicit price function is different for each property market, the welfare estimates are market specific, and aggregating such effects would need to reflect simplifying assumptions about distribution of incomes and price responses and/or introduce methods to validate BT. The authors did not find theoretical justification for using the BT method in their study, thus they investigated each landfill site independently. Chattopadhyay (2003) applied HPM to amenity improvements, including air pollution, to examine the performance of BT methods in a statistically controlled, repeated sampling scheme, using a Chicago housing sample. In contrast to Atkinson and Crocker (1992), the author argued that even under perfect statistical conditions, the quality of transferred estimates was poor for both the BFT and UVT, with a slight advantage to the BFT (average TER was $30 \%$ ). He emphasized that the poor quality of the data (especially the problem of multicollinearity) might cause these transfer performances. Nonetheless, the findings show that transfer performance gets better when sample size becomes larger. Smith and Huang (1995) examined 86 estimates of marginal WTP for reduction in air pollution (measured by particulate matter) through a review of 37 HPM studies developed between 1967 and 1988 in different areas in the USA. They performed statistical tests to explain the variation in the estimates and concluded that differences of marginal WTP across the cities can be substantial due to variations in local conditions, and they depend largely on market conditions and the procedures used to implement the hedonic models. They also developed BT to four of the entire cities using UVT as well as transferring meta-functions. The results suggested that using meta-analysis can improve transfer of HP benefit estimates, but the method is sensitive to the level of environmental quality and the demographic characteristics of the population. Another important result of this study was that estimates of WTP from the hedonic studies were uniformly lower than those based on damage functions using the value-of-statistical-life method to value the mortality impact of particulate matter. Johnson and 
Button (1997) looked at some of the limitations of BT using the noise-nuisance aspect of airport investment policy assessment as an illustrative case. They examined 18 HPM studies that placed monetary values on airport noise-nuisance using a simple meta-regression analysis. The studies were conducted in different countries (although most were in the USA) in various years (1979-1993). The authors argued that the results of the meta-analysis exercise indicate that there was little justification for applying BT to the context of airport noise-nuisance at that time mainly because of the difficulty of explaining the wide range of the existing values. Brouwer (2000) reviewed and analyzed several HP, TC, and CV studies that used BT for new estimates. The HP models that he examined have been used to detect the influence of air pollution on house prices. He concluded that differences in the results of different HP studies could be related to dissimilar research designs. Most of the differences seemed to originate from the specific model used, statistical estimation method, inclusion or exclusion of specific explanatory variables, definition of these variables, and data quality. Atkinson and Crocker (1992) examined the transferability of hedonic functions across different markets. Their results showed that only similarities in the structural attributes across markets such as in the type and level of the amenity, socioeconomic characteristics, and geographic factors, allow transfer of hedonic marginal price functions across markets.

\section{Description of the Primary Study ${ }^{1}$}

\subsection{TRANSFER STATIONS AND THE DATABASE}

Waste transfer stations play an important role in a community's waste management system, serving as the link between a community's solid waste collection program and a final waste disposal facility. The research we use for BT tests evaluated the effects that disamenities related to waste transfer stations have on residents located at different distances from the facilities. The evaluation was based on the real estate market, which captures changes in parameters of environmental quality, such as bad smell emitted from transfer stations, noise, litter, visual intrusion, and any associated perceived discomfort. We applied the HPM and looked at marginal changes in real estate values associated with additional "units" of transfer station-related nuisance. Due to lack of data, we did not include across space the levels of odor, noise, and other disamenities for each observation (dwelling unit); thus, it was not possible to estimate each individual impact. Instead, as it is common in hedonic studies, we referred to the proximity to a transfer station as a proxy for the entire environmental impact, since it is commonly expected that these disamenities would decay over space as a linear or non-linear function. By employing econometric tools, we calculated the spatial extent of 
the impact and the environmental damage of transfer stations in four cities in Israel as revealed through the decrease in housing values at various distances from the transfer stations. The cities were: Bet-Shemesh, Rehovot, RishonLeziyyon, and Petah-Tiqwa. Bet-Shemesh is located in the vicinity of Jerusalem; the other three transfer stations are located in cities within the second tier of cities surrounding the dense metropolitan area of Tel-Aviv.

In order to apply the HPM, a database was constructed, including realestate asking prices, distances of each of the properties away from the transfer stations as well as characteristics of the houses and related neighborhoods. Data were obtained from the Israeli Central Bureau of Statistics (CBS) and GIS (Geographical Information System) databases. The data on the dwelling unit values for the four cities from 2001 to 2004 were obtained from a commercial real-estate database that regularly serves real-estate agents. The database contains information on houses' asking prices as well as characteristics of the properties. Clearly, actual sales prices are the preferred prices for the hedonic function, though; we used asking prices because this was the only available information we could obtain. ${ }^{2}$

\subsection{SITE CHARACTERISTICS}

The investigated transfer stations differ from one another in size and other characteristics. For example, the facility in Petah-Tiqwa is not the largest in terms of area, but treats a daily amount of 700 tons of waste. Although this facility is at the greatest distance from the closest dwelling units, there are many complaints regarding disamenities it creates. The only roofed facility is in Rishon-Leziyyon, which is also the newest and most up-to-date facility. Only two of the transfer stations, in Rehovot and Rishon-Leziyyon, use compaction devices and except for the facility in Bet-Shemesh, they all have sorting activity. None of the facilities activates an under-pressure device to eliminate odors.

Based on our speculation about the limited extent of disamenities impact (verified by repeated regressions), we deleted the transactions farther than $4 \mathrm{~km}$ from the transfer stations and concluded with about 9,000 observations (Bet-Shemesh - 346, Rehovot - 2,904, Rishon-Leziyyon - 1,968, PetahTiqwa - 4,287). The values obtained (both quantitative and dummies) are similar to the mean of the characteristics of the original data set based on about 16,000 observations in a radius of $9 \mathrm{~km}$ from the sites.

\subsection{RESULTS OF THE HPM MODEL}

Based on the market-segmentation assumption for the hedonic analysis (e.g. Cambridge Econometrics et al. 2003; Brasington and Hite 2004), a separate 
hedonic house price function was estimated for each of the four markets. For econometric analysis we estimated also a HPF for the pooled data of all cities as one aggregated market. Seven different parameter estimates were generated for the relationship between features of property characteristics and house price. Some explanatory variables that were considered in preliminary specifications were dropped for different statistical reasons. Some variables were also omitted because we aimed to use the same basic explanatory variables in all four cities that would be strong predictors of WTP. (Still, unfortunately, the Year variable is missing for Bet-Shemesh, and two variables' coefficients are not statistically significant there; these will affect the below BT tests.)

Several functional forms were examined to specify the HPFs. Testing indicated that specifying the dependent variable (hedonic price) as a natural logarithm improved the explanatory power of the models, and this transformation, with an additional term including the distance squared (SQUARDI), was employed throughout our regression analysis as the prime model.

Equation 4 shows the "quadratic semi-log model" (quadratic distance model) that was selected:

$$
\begin{aligned}
\operatorname{Ln}(\text { PRICE })= & \beta_{0}+\beta_{1}(\text { DISTANCE })+\beta_{2}(\text { SQUAR-DI }) \\
& +\beta_{3}(\text { FLOOR-SIZE })+\beta_{4}(\text { CLUSTER })+\beta_{5}(\text { TYPE }) \\
& +\beta_{6}(\text { PARKING })+\beta_{7}(\text { ELEVATOR })+\beta_{8}(\text { YEAR })+\varepsilon .
\end{aligned}
$$

The meaning of each of the variables in the function is shown in Table I.

The use of the quadratic function is based on the notion that the effect of disamenities from a transfer station does not decrease linearly with distance, but after a certain distance the effect vanishes. Under the disamenity hypothesis, a positive coefficient on DISTANCE and a negative coefficient on SQUAR-DI would reflect a location expense that decreases with distance at a diminishing rate, allowing the function to have a maximum point.

The regressions of the quadratic semi-log model attained relatively high values of $R^{2}$ across all sites and in the pooled data as well (average $R^{2}=0.74$ ), and high $F$ values, both indicating a strong significant regression model, and with a significance level for most estimates of less than $5 \%$. The coefficient of the variable DISTANCE, the proxy for the environmental impact, was statistically significant across all sites and had the expected positive sign. This evidence ratified our basic hypothesis that closeness to transfer stations is perceived as a disamenity and that disamenities have an influence on residential value. Thus, properties located in close proximity to transfer stations have lower values compared to similar properties located in more remote areas. 
Table I. Description of the variables in the hedonic model

\begin{tabular}{|c|c|c|c|c|}
\hline Variable & Unit/range & Description & Source of data & $\begin{array}{l}\text { Expected } \\
\text { sign }\end{array}$ \\
\hline PRICE & US\$ & $\begin{array}{l}\text { Asking price of the } \\
\text { dwelling unit }\end{array}$ & Real-estate database & + \\
\hline DISTANCE & $\mathrm{km}$ & $\begin{array}{l}\text { Distance from a residence } \\
\text { to a transfer station }\end{array}$ & GIS & + \\
\hline SQUAR-DI & $\mathrm{km}^{2}$ & DISTANCE squared & & - \\
\hline CLUSTER & $1-20$ & CBS cluster rank & CBS & + \\
\hline FLOOR-SIZE & $\mathrm{m}^{2}$ & $\begin{array}{l}\text { Total space of } \\
\text { apartment/house }\end{array}$ & Real-estate database & + \\
\hline TYPE & $0 / 1$ & $\begin{array}{l}\text { Apartment }=0, \text { Single } \\
\text { family-home }=1\end{array}$ & Real-estatedatabase & + \\
\hline PARKING & $0 / 1$ & $\begin{array}{l}\text { Residence with garage } \\
(1=\text { yes, } 0=\text { no })\end{array}$ & Real-estate database & + \\
\hline ELEVATOR & $0 / 1$ & $\begin{array}{l}\text { Building has elevator } \\
(1=\text { yes, } 0=\text { no })\end{array}$ & Real-estate database & + \\
\hline YEAR & $0 / 1$ & $\begin{array}{l}\text { Age of building: before } \\
1990=0, \text { after } 1990=1\end{array}$ & Real-estate database & + \\
\hline
\end{tabular}

The determination of the relationship between changes in environmental quality-level and property prices was based on regression results from different models (in addition to the prime quadratic distance model). The results showed that an additional $1 \%$ average distance of a house from the local transfer station was associated with a $0.06 \%$ rise in the price of the average house. The maximum spatial extent of impact of disamenities was about $2.8 \mathrm{~km}$ away from a transfer station, with an increase of about $\$ 5,000$ to house value per $\mathrm{km}$ away from the site.

\section{Methodology of the Benefit Transfer Analysis}

In the current study we tested the robustness and validity of transferal of hedonic benefit functions across sites, and thus we would be able to deal with the doubts about the implementation of BT in hedonic studies that exist mostly because of the segmented character of property markets. We used the BFT approach mainly because it transfers more information about local preferences than other transfer approaches. Because we calculated and used for the analysis different hedonic functions in different combinations from the four samples, the process can be considered a "mini-MFT". 


\section{EXPLORING BENEFIT TRANSFER}

For practical implementation, the basic idea of the following exercises was to examine whether we could predict housing prices (which was the WTP for the property) in a vicinity of a policy transfer station, based on existing estimates of housing prices in the surrounding area of other transfer stations in different locations. The predicted values can be used to obtain the value of disamenities damage that this transfer station generated. Counter to nearly all of the reviewed studies in Sections 2.4 and 3.1, the study we conducted was built in advance on the aim of examining the performance of BT, and as such, the HPFs at the investigated sites (except Bet-Shemesh) were based exactly on the same explanatory variables and the entire analysis was identically designed; this paper therefore has an advantage.

\subsection{CHOW AND WALD TESTS}

Prior to the transferability assessment we examined a basic statistical data requirement for a valid $\mathrm{BT}$. We used the Chow and Wald tests to examine the variability among the original case studies and to explore the extent to which the variability could be explained and allowed in subsequent transfers. First, equality of parameters across samples was examined by the likelihood ratio of the Chow test, which tests the equality between sets of coefficients in two (or more) linear regressions (by computing the ratio of the difference between the sum of squares of the residuals assuming equality and the sum of squares without assuming the equality) (Chow 1960; Hanley et al. 2006). The Chow test pools all observations from all sites and then tests whether functions obtained solely from any given survey site are significantly different from that of the pooled model. In other words, the question we wanted to examine was whether the relationship holds for the different groups of economic units. Statistically, this question can be answered by testing whether the four sets of observations can be regarded as belonging to the same regression model. Optimally, if the parameters were numerically identical for the different samples, then it would be acceptable to estimate the WTP from the pooled samples and apply the estimate to each of the samples. It may be more reasonable to suppose that only parts of the relationships are identical, thus, subsets of coefficients in the regressions are statistically equal.

Second, we performed an application of the Wald test. Brouwer and Bateman (2005) argue that the Wald test is more suitable for examination of the data for BT. Instead of pooling data, coefficients of particular explanatory variables of a transferred function based on a study site are tested against coefficients of parallel variables in the function of a policy site. It evaluates whether each of the coefficients of the explanatory variables are statistically the same between each two models. 
TZIPI ESHET ET AL.

\subsection{BENEFIT TRANSFER TESTS}

The core of the tests involves the transfer of WTP estimated-parameters across the primary sites. The methodology we use to test the performance of the BFTs is outlined in Figure 1.

As Figure 1 illustrates, the starting point for the tests was the hedonic functions (WTP) that were estimated in four primary valuation studies at four policy sites as described above (the functions obtained via quadratic semi-log model were used). The transferability was tested in two directions, i.e., all sites were used both as policy and study sites. Say, each site in turn was treated as the target site (policy study) of a BT exercise that is the site for which a benefits estimate is needed. In each test $\mathrm{WTP}_{P 0}$ stands for a different policy site, and $\mathrm{WTP}_{S 1}, \mathrm{WTP}_{S 2}$, and $\mathrm{WTP}_{S 3}$ stand for each of the other study sites. To broaden the transfer tests, pooled functions $\left(\mathrm{WTP}_{S p l}\right)$ were also estimated based on hedonic regressions of different combinations of the sites, depending on the employed exercise; using all data from all sites other than the target site (the source sites), and using mean values for independent variables from appropriate target site. By repeating the test for all possible transfers with a mix of similar and dissimilar samples, we built up a richer picture of where transferability is feasible and where it is not.

We test the principal hypothesis of BFT that the predicted value generated by a function (WTP $\left.p_{0} / s\right)$ that combines the coefficients $\left(\beta_{s}\right)$ of the HPM function estimated at the study site, with the policy site characteristics (explanatory variables $-X_{p_{0}}$ ) is equal to the value that would be obtained from a direct study at the policy site (WTP $\left.p_{0}\right)$, as follows in equation 5:

Ho : $\quad$ transferred $\mathrm{WTP}_{p_{0} / s}=f\left(\beta_{s_{0}}, X_{p_{0}}\right)=\mathrm{WTP}_{p_{0}}$.

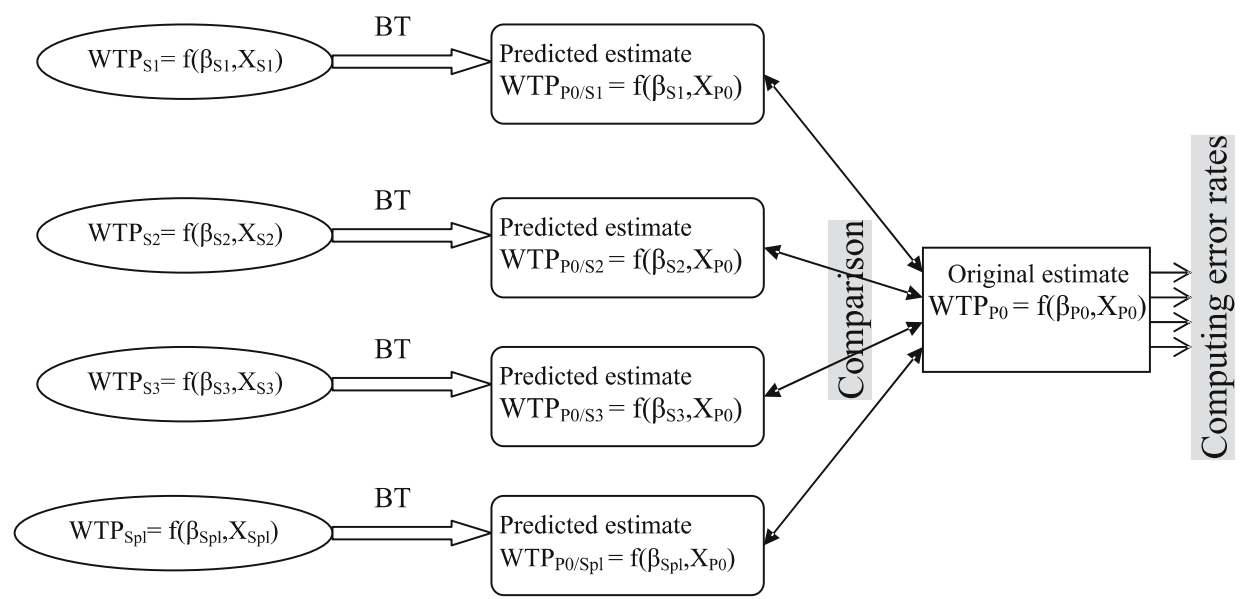

Figure 1. An illustration of the methodology of the tests of BFT. 


\section{EXPLORING BENEFIT TRANSFER}

To examine the hypothesis, the original WTP $p_{0}$ value that was actually obtained at the policy site was then compared to the predicted WTP value that was transferred to the policy site from the other studies. This procedure assumes that the primary study at the policy site provides the "true" impact estimate. Obviously, equal estimates are the objective of the experiments. Actually, BFT aims to produce a WTP value close to the "true" estimate, and as the bias is smaller, BT will be more satisfactory. This closeness was measured by transfer error rates (TER). Percentage errors were calculated for each of the exercises as follows:

$$
\mathrm{TER}=\left(\left(\mathrm{WTP}_{p_{0} / s}-\mathrm{WTP}_{p_{0}}\right) / \mathrm{WTP}_{p_{0}}\right) * 100
$$

To fulfill the study objectives that included the examination of the sensitivity of benefit transfer action to the explanatory variables employed in the surveys as well as to the structure of the initial data, and thus to examine the basic condition for a valid BT demanding large similarity between sites in terms of population and site characteristics, we conducted statistically controlled exercises. That is, the above procedure (in Figure 1) was performed on different groups of benefit functions generated by the same hedonic regression model but on different derivations of the observations, as follows:

Scenario 1: Transferability was tested on the basic survey sample that included all (uncontrolled) observations (regression results in Eshet et al. 2006). This scenario was divided into two parts:

Scenario 1A: Transferability was tested between the three samples that have precisely the same hedonic function (including all seven explanatory variables). These are the sites in Rishon-Leziyyon, Petach-Tiqwa, and Rehovot.

Scenario 1B: Transferability was tested between all four sites including the sample of Bet-Shemesh. One of the variables, The Year variable, is missing for Bet-Shemesh, and was available for other sites. Besides, some variables' coefficients are not statistically significant in Bet-Shemesh, probably due to the sample size that is relatively small. It was our interest to examine if and how this situation affects the BT process.

Scenario 2: To test the sensitivity of BFT to population characteristics, the sample in each city was sorted by the CLUSTER variable that stands for the socioeconomic characteristics of the neighborhoods. Then, each sample was divided into two groups resulting with two sub-samples: "poor" households and "wealthy" households. The transfer exercises were then performed separately between "poor" samples and "wealthy" samples across the sites.

Scenario 3: To test the sensitivity of BFT to city characteristics, the property markets were addressed. The basic sample in each city was divided into 
two sub-samples: one included observations of single family-homes, and the other - apartments only. The transfer experiments were then performed separately between the different groups of property types across the sites.

\section{Results $^{3}$}

\subsection{EQUALITY TESTS}

As mentioned above, the degree of similarity between the parameters $(\beta)$ of the different samples referring to the pooled data was tested using the Chow test that produces parameters of $F$ statistic and log likelihood ratios. The test was performed for different combinations of the full sample. In all cases, the $F$ statistic and $\log$ likelihood ratio values were relatively large (108.4 and 2,310.9, respectively, for the case of all sites) and with significance levels less than $5 \%$, indicating that the hypothesis of statistically equal equations was rejected. Nonetheless, as the samples became more similar, the $F$ statistic and log likelihood ratio values became smaller (i.e., when the pooled sample included only the sites of Rishon-Leziyyon and Petach-Tiqwa, the $F$ statistic was 45.1 and $\log$ likelihood ratio was 394.9).

After testing the WTP function of each site against the pooled function, we performed a Wald test to test the equality of each individual explanatory variable, between two sites at a time, in all combinations and between each site and the pooled model.

The null hypothesis was:

$\mathrm{H} 0: \beta_{i}=\beta_{j} \quad i=(1,2,3,4) \quad j=(1,2,3,4) \quad i \neq j$.

The null hypothesis was rejected in many of the tests; however, the results are in the same line with the Chow test and like the findings and conclusions that we found later on. Each test revealed different subsets of significantly equivalent coefficients. For example, three of the coefficients were found to be statistically equal between the sites of Rishon-Leziyyon and Petach-Tiqwa at a significance level of $95 \%$ ( $F$ statistic: CLUSTER - 0.0026, DISTANCE 0.0064, PARKING - 0.0047), confirming the outcome of the Chow test about the highest similarity between these sites. Regarding coefficients of the pooled model, a significant equality was obtained between Petach-Tiqwa and the pooled model for five variables at a significance level of $95 \%$ ( $F$ statistic: CLUSTER - 0.5790, DISTANCE - 0.8206, SQUAR-DI - 0.6663, FLOORSIZE - 0.6636, and the Constant - 0.0715).

Although the results of the Chow and Wald tests apparently showed that the hedonic functions of the case studies were not statistically equal (as some 
of the variables were statistically equal and some were not), we decided to proceed with the exercise of transferring valuations using BT.

\subsection{PERFORMANCE OF BENEFIT TRANSFER}

The performance of BT was examined in all directions for the scenarios discussed above. However, we report here only an illustration of the results. (It is worth noting that in the transferred functions we included the mean values of each explanatory variable. However, we conducted the same procedure where a predicted function was generated for each individual observation and then the average WTP of all functions was calculated. Both ways produced similar values.)

Scenario 1A. Table II summarizes the findings of one inclusive route of functions transfer of Scenario 1A that was the core of the study and included all observations in three similar samples.

Follows an illustration of a single BT action in Table II from Petach-Tiqwa to Rishon-Leziyyon: Column (1) that shows the coefficients of Rishon-Leziyyon' original function is presented for comparison only. Column (2) stands for the mean values of the explanatory variables of the target site that is RishonLeziyyon. Column (3) stands for the coefficients of the explanatory variables from the function of Petach-Tiqwa. Column (4) that stands for the predicted Function1 for Rishon-Leziyyon was obtained via multiplying each of the mean values in Column (2) by each corresponding coefficient in Column (3). The predicted average price was calculated using Function1, resulting with a value of US $\$ 210,238$. Then, the deviation of this value from the "true" average price in Rishon-Leziyyon that is US\$201,793, was calculated resulting with a transfer error rate of $4.2 \%$. Function 2 and Function 3 were similarly carried out using the fitting columns.

It stands out that the smallest absolute TER was obtained when the BFT to Rishon-Leziyyon was carried out from the pooled samples of Rehovot and Petach-Tiqwa. Among the two sites, the smaller absolute TER was obtained from the function of Petach-Tiqwa. The results of the calculation of the TER for Scenario 1A of all BFTs between three sites and the pooled data of two sites in turn, are summarized in Table III.

Percentage errors for BT involving the three sites and the pooled data range from $-21 \%$ to $+29 \%$. In absolute terms it is between $1.3 \%$ and $29 \%$. An overall absolute average TER of all transfers is $15.4 \%$. It is outstandingly conspicuous that the best performance of BFT was obtained between the two relatively similar cities, Rishon Leziyyon and Petach-Tiqwa, rather symmetrically, with very low TERs. The TER is $2 \%$ from Rishon-Leziyyon to Petach-Tiqwa and 4\% in the opposite direction (these may be considered almost the same estimates). The phenomenon of asymmetry in BT is revealed 
TZIPI ESHET ET AL.

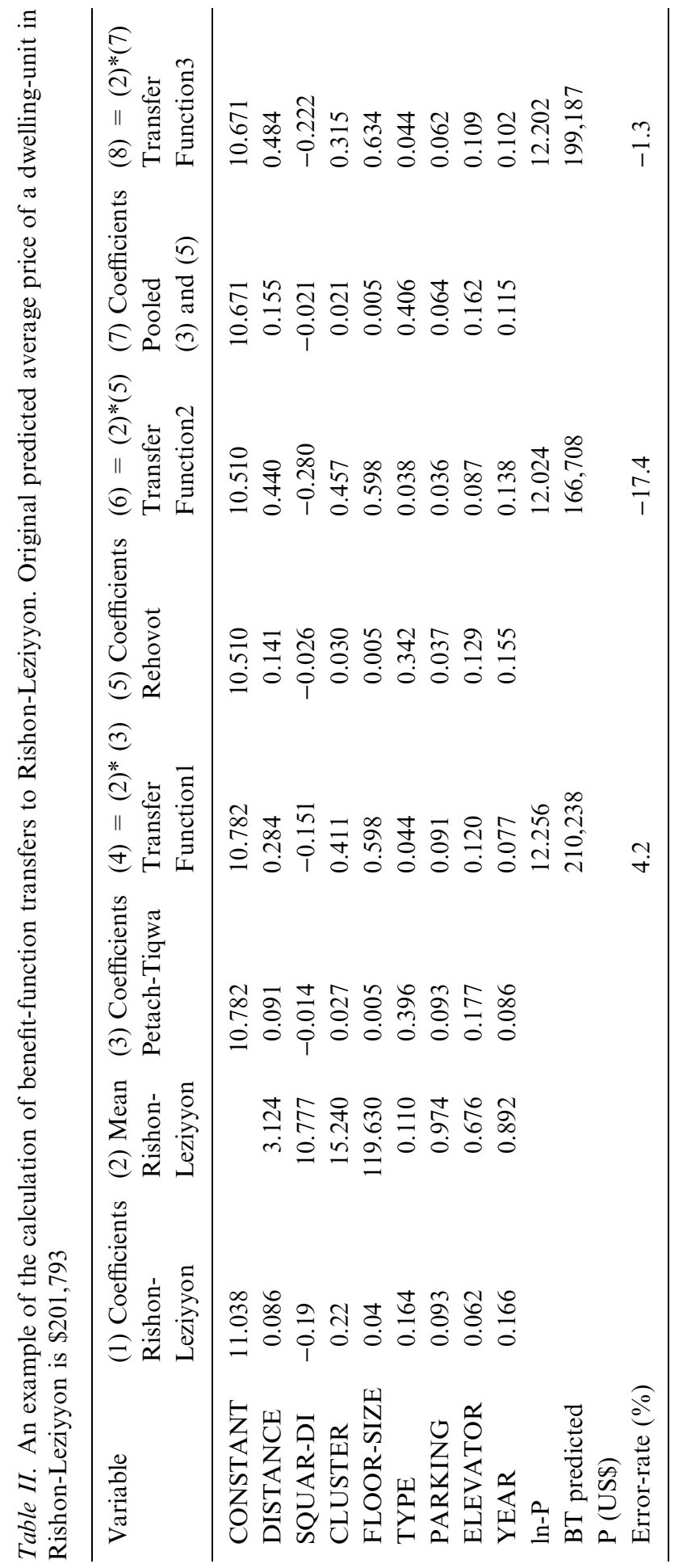


Table III. A summary of all transfer error-rates (\%) from Scenario $1 \mathrm{~A}$

\begin{tabular}{lcccc}
\hline Transfer from & \multicolumn{3}{l}{ Transfer to } & \\
\cline { 2 - 5 } & Rehovot & $\begin{array}{l}\text { Rishon- } \\
\text { Leziyyon }\end{array}$ & Petach-Tiqwa & $\begin{array}{l}\text { Average } \\
\text { error-rate } \\
\text { (absolute) }\end{array}$ \\
\hline Rehovot & $*$ & -17.4 & -21.0 & 19.2 \\
Rishon-Leziyyon & 29.0 & $*$ & 2.0 & 15.5 \\
$\begin{array}{l}\text { Petach-Tiqwa } \\
\text { Rishon-Leziyyon + Petach-Tiqwa } \\
\text { Rehovot + Petach-Tiqwa }\end{array}$ & 26.1 & 4.2 & $*$ & 15.1 \\
$\begin{array}{l}\text { Rishon-Leziyyon + Rehovot } \\
\text { Average Transfer Error-rate }\end{array}$ & 26.8 & -1.3 & & \\
to each individual site (absolute) & & 7.6 & -3.3 & \\
\hline
\end{tabular}

in all cases. Nonetheless, the smallest asymmetry was found between Rishon Leziyyon and Petach-Tiqwa, which are, as already noted, the most similar in their characteristics.

Compared to other studies in the literature, the TERs in this scenario are remarkably lower in some cases. This is probably due, above all, to a wellstructured survey that was specifically planned for BT examinations.

Scenario $1 B$. In this exercise the transfer is performed between four sites: the three sites from Scenario 1A and Bet-Shemesh as well. Besides fundamental differences from the above three cities in the location and the characteristics of Bet-Shemesh, the sample of Bet-Shemesh lacks the Year variable that was highly significant in the other three sites, and the Parking and Elevator variables were not significant for Bet-Shemesh, unlike the other cities. In addition, the sample is very small compared to the other samples. Thus, the aim of the current exercise was to investigate the transfer of values between a dissimilar sample and a group of similar samples, and to examine how the results of the BT tests are affected.

The results of the calculation of the TER for Scenario 1B of all BFTs between all sites and the pooled data of three sites in turn, are summarized in Table IV.

Table IV reveals our earlier expectation about the performance of the transfer of functions with the additional site of Bet-Shemesh. The TERs mostly increased compared to Scenario $1 \mathrm{~A}$. An overall absolute average TER of all transfers is $19 \%$ compared to $15.4 \%$ in Scenario 1A. It is noticeable that transfers from Bet-Shemesh to the other cities underestimate their values and result in the largest absolute average TER (31\%), and indeed this is the smallest city with the largest divergence from the other three cities, far away 
Table IV. A summary of all transfer error-rates (\%) from Scenario $1 B$

\begin{tabular}{|c|c|c|c|c|c|}
\hline \multirow[t]{2}{*}{ Transfer from } & \multicolumn{5}{|c|}{ Transfer to } \\
\hline & Rehovot & $\begin{array}{l}\text { Rishon- } \\
\text { Leziyyon }\end{array}$ & $\begin{array}{l}\text { Petach- } \\
\text { Tiqwa }\end{array}$ & $\begin{array}{l}\text { Bet- } \\
\text { Shemesh }\end{array}$ & $\begin{array}{l}\text { Average } \\
\text { error-rate } \\
\text { (absolute) }\end{array}$ \\
\hline Rehovot & $*$ & -17 & -21 & -4 & 14 \\
\hline Rishon-Leziyyon & 29 & $*$ & 2 & 25 & 18 \\
\hline Petach-Tiqwa & 26 & 4 & $*$ & 28 & 19 \\
\hline Bet-Shemesh & -18 & -46 & -29 & $*$ & 31 \\
\hline $\begin{array}{l}\text { Rishon-Leziyyon }+ \text { Petach- } \\
\text { Tiqwa }+ \text { Bet-Shemesh }\end{array}$ & 18 & & & & \\
\hline $\begin{array}{l}\text { Rehovot }+ \text { Petach- } \\
\text { Tiqwa }+ \text { Bet-Shemesh }\end{array}$ & & 6 & & & \\
\hline $\begin{array}{l}\text { Rishon-Leziyyon }+ \\
\text { Rehovot }+ \text { Bet-Shemesh }\end{array}$ & & & -21 & & \\
\hline $\begin{array}{l}\text { Rishon-Leziyyon }+ \text { Petach- } \\
\text { Tiqwa }+ \text { Rehovot }\end{array}$ & & & & 1 & \\
\hline $\begin{array}{l}\text { Average transfer error-rate } \\
\text { to each individual } \\
\text { site (absolute) }\end{array}$ & 23 & 18 & 18 & 14 & \\
\hline
\end{tabular}

from the populated metropolitan area of Tel Aviv, and additionally, as was emphasized above, its model lacks satisfactory data, a fact that probably affected the results. Note, however, that the procedure is not symmetric, that is, the transfers to Bet-Shemesh (over or under-estimate) yield the smallest absolute average TER (14\%).

Scenario 2. In this exercise we tested the sensitivity of BFT to population characteristics controlled by the CLUSTER variable as explained above. The results show a significant improvement in the performance of most of the BFTs. Some figures can demonstrate this improvement: TER from Rehovot to Petach-Tiqwa decreased from $(-21 \%)$ in Scenario 1A to $(-15 \%)$ in BFT for the "poor" samples and to $(-13 \%)$ for the "wealthy" samples, and yet, the "true" value was underestimated via the procedure in both episodes. Another example would be for a transfer of pooled-data estimates: TER from the pooled samples of Rishon-Leziyyon, Rehovot, and Bet-Shemesh to Petach-Tiqwa decreased from $(-21 \%)$ in Scenario 1B to $(-15 \%)$ in BFT for the "poor" samples and to $(-9 \%)$ for the "wealthy" samples.

Scenario 3. In this exercise we tested the sensitivity of BFT to some housing characteristics, controlled by the TYPE variable (single familyhomes versus apartments) as explained above. In this experiment, improvement of the BFT was observed in some cases only. For example, TER obtained from Rehovot to Rishon-Leziyyon decreased from $(-17 \%)$ in 
Scenario 1A to $(-13 \%)$ in BFT for the "apartments" samples, and in the opposite direction, from Rishon Leziyyon to Rehovot, the TER decreased from $29 \%$ in Scenario 1A, to $19 \%$. We believe that the inconsistency in the findings of this scenario can mainly be attributed to the number of observations in the separate TYPE-samples that were not balanced across the sites as most of the observations referred to apartments.

\section{Conclusions}

The potential "legitimateness" of the BT approach has been a focus of attention for researchers. During the last decade, a number of studies have been carried out to test the functioning of the BT process and the quality of its results, in order to examine the potential of using existing valuations to predict specific environmental preferences (and WTP) in new policy contexts. However, tests of such processes with HPM estimates are rare. This paper provides further empirical evidence of the performance of BT based on HPM studies. In contrast to the doubts that are often argued regarding the feasibility of transferring between sites disamenities estimates that were obtained via hedonic studies, our study provides sound evidence of the validity of such a procedure as well as its limitation. The specific contribution of this paper, compared to prior analyses of BT using hedonic models, is in employing data and results from a study that was designed with a BT validity test in mind.

Although statistical tests we performed showed that most of the hedonic functions were not significantly equal, the findings of the study suggest that many of the benefit functions are transferable across the cities. Note that even for the lowest TERs of $2 \%$ and $4 \%$ between Rishon-Leziyyon and Petach-Tiqwa the null hypothesis of equality was rejected for some of the coefficients. Thus, we argue that statistical tests are an important tool for examining the basic structure of the data regarding the degree of similarity between samples, but a statistical inequality outcome does not necessarily robustly invalidate transfers of environmental values across studies.

Overall findings of the study are broadly in line with prior expectations. The exercises we performed confirm the hypothesis that a successful BT of HPM estimates requires similarity in the structural attributes across markets with respect to: the type of amenity for which benefits may be transferred and the magnitude of this amenity, statistical properties of the magnitude of socioeconomic factors of the population and geographic and other exogenous factors of the sites. Difference in site characteristics can influence the level of disamenity experiences and apparently can cause substantial biases in BT estimates. Indeed, TERs were smaller for BT between relatively similar cities in terms of site, size, and location, and between more similar 
sub-samples in the aspect of socioeconomic characteristics and housing type. Note, however, that BT worked better in one direction than the other (transfer asymmetry).

Generally, compared to other studies in the literature, we obtained in some cases remarkably lower TERs as the $2 \%$ and $4 \%$ errors resulted from the transfer between Rishon-Leziyyon and Petach-Tiqwa in both directions, and as the $(-1.3 \%)$ from the transfer in Scenario 1A from the pooled sample of Rehovot and Petach-Tiqwa to Rishon-Leziyyon. As our case studies were planned in advance to examine the performance of BT we can attribute the relatively low TERs in Scenario 1A mainly to the well-structured survey. Separating the main exercise into two cases (Scenario 1A and Scenario 1B) allowed us to examine the influence of "good" and "bad" samples on the results of BT practice. Consequently, we recommend that even when a study is case-specific, its potential application in BT for another study should be considered, regarding the survey method, the explanatory variables employed (including only generic variables that according to theory would be strong predictors of WTP and will formulate the optimal transfer function) and the way the results are reported. Studies should be more systematic so that the results presented may be assessed more completely by anyone wanting to consider them for a BT practice. Notwithstanding, one should keep in mind that in actual application of BT we do not know the "true" benefit function at the policy site and some specification error will be unavoidable.

The relatively low TERs imply that the BT method can be appropriate for transferring disamenity values and thus estimation of environmental damage between transfer station sites in Israel; though, this should always be applied with extra caution. Relatively immediate estimation of the influence that the location of transfer stations has on surrounding property values can assist policy makers in municipalities regarding the siting of such waste facilities.

The question of the validity of functions' transfer as well as the level of error rate must be viewed according to the use of the transfer results. Indeed, we share the assertion of other researchers (e.g., ODPM 2002; Barton 2002) that if BT is used for policy contexts such as screening and even ranking projects or prioritizing, to get an indication of the order of magnitude of an environmental impact, a larger error of magnitude could be acceptable than if the transfer is conducted, for example, for calculating marginal social cost and determining damage compensation. The latter requires higher levels of reliability that are still questioned even for primary non-market valuation studies. However, there is no rule of thumb about the acceptable levels of TER, and thus what level of error rate is low enough for each decision and practice remains questionable, and as long as no satisfactory guidance exists, there can only be ad hoc decisions. Policy makers should always consider the trade-off between a risk of under/over-estimated values by using BT 
estimates and saving in time and money resources of conducting a primary study (or even not performing a study at all). Thus, decisions based on imperfect information could be preferable to no decisions at all.

The study concludes that from a conceptual point of view, and based on the results of this research as well as on past experiences, BT has become a key factor in up-to-date evaluation of externalities in all environmental areas.

\section{Notes}

1. A full description of the primary study can be found in Eshet et al. (2006).

2. It is noteworthy that the specific housing-prices database is not based on assessors' or real estate agents' judgment, but on sellers' asking prices as appear in newspapers' advertisement, which is what one should seek to get, being a measure of people's preferences. Furthermore, according to a study conducted in Israel, the negotiation difference between asking price and transaction price of residential real-estate (in Israel) is only $6-10 \%$ (Ministry of Justice 2003). Thus, the effect of using asking prices instead of transaction prices is not significant for the BT tests.

3. Full numerical results of statistical tests and all BT functions and tests are available by request from the authors.

\section{References}

Alberini, A., M. Cropper, A. Krupnick, J.-T. Liu, D. Shaw and W. Harrington (1995), 'Valuing Health Effects of Air Pollution in Developing Countries: The Case of Taiwan', Discussion paper 95-01: Resources for the future, Washington, DC.

Atkinson, S. E. and T. D. Crocker (1992), 'The Exchangeability of Hedonic Property Price Studies', Journal of Regional Science 32(2), 69-83.

Barton, D. N. (2002), 'The Transferability of Benefit Transfer: Contingent Valuation of Water Quality Improvements in Costa Rica', Ecological Economics 42, 147-164.

Bateman, I., R. Carson, B. Day, M. Hanemann, N. Hanley, T. Hett, M. Jones-Lee, G. Loomes, S. Mourato, D. Pearce, R. Sugden and J. Swanson (2002), Economic Valuation with Stated Preference Techniques, A Manual. UK \& USA: Edward Elgar.

Beloff, B. R., E. R. Beaver and H. Massin (2000), 'Assessing Societal Costs Associated with Environmental Impacts', Environmental Quality Management, winter 2000.

Boardman, A. E., D. H. Greenberg, A. R. Vining and D. L. Weimer (2001), Cost-Benefit Analysis: Concept and Practice. Upper Saddle River, NJ 07458, USA: Prentice Hall.

Boyle, K. J. and J. C. Bergstrom (1992), 'Benefit Transfer Studies: Myths, Pragmatism and Idealism', Water Resources Research 28(3), 657-663.

Brasington, D. M. and D. Hite (2004), 'Demand for Environmental Quality: A Spatial Hedonic Analysis', Regional Science and Urban Economics 35(1), 57-82.

Brisson, I. and D. Pearce (1995), 'Benefit Transfer for Disamenity from Waste Disposal'. CSERGE Working Paper WM.

Brouwer, R. (2000), 'Environmental Value Transfer: State of the Art and Future Prospects', Ecological Economics 32, 137-152. 
Brouwer, R. and I. Bateman (2005), 'Benefit Transfer of Willingness to Pay Estimates and Functions for Health Risk Reductions: A Cross-country Study', Journal of Health Economics 24, 591-611.

Brouwer, R. and F. Spaninks (1999), 'The Validity of Environmental Benefits Transfer: Future Empirical Testing', Environment \& Resource Economics 24, 95-117.

Brouwer, R., I. H. Langford, I. J. Bateman and R. K. Turner (1999), 'A Meta-analysis of Wetland Contingent Valuation Studies', Regional Environmental Change 1(1), 47-57.

Cambridge Econometrics, EFTEC and WRc (2003), 'A Study to Estimate the Disamenity Costs of Landfill in Great Britain', http://www.defra.gov.uk.

Chattopadhyay, S. (2003), 'A Repaeted Sampling Technique in Assessing the Validity of Benefit Transfer in Valuing Non-Market Goods', Land Economics 79(4), 576-596.

Chow, G. C. (1960), 'Tests of Equality Between Sets of Coefficients in Two Linear Regressions', Econometrica 28, 591-605.

Downing, M. and T. Ozuna (1996), 'Testing the Reliability of the Benefit Transfer Function Transfer Approach', Journal of Environmental Economics and Management 30, 316-322.

Eshet, T., M. G. Baron, M. Shechter and O. Ayalon (2006), 'Measuring Externalities of Waste Transfer-Stations in Israel, Using Hedonic Pricing', Waste Management - International Journal of Integrated Waste Management, Science and Technology (in press).

EC (European Commission, DG Environment) (2000), A Study on Economic Valuation of Environment Externalities from Landfill Disposal and Incineration of Waste. Final Appendix report, Website: http://europa.eu.int/comm/environment/waste/studies/ econ_eva_landfill.htm.

EVRI (The Environmental Valuation Reference Inventory) Website:http://www.evri.ec.gc.ca/ EVRI/english/about.htm.

Hanley, N., R. E. Wright and B. Alvarez-Farizo (2006), 'Estimating the Economic Value of Improvements in River Ecology Using Choice Experiments: An Application to the Water Framework Directive', Journal of Environmental Management 78, 183-193.

Jiang, Y., S. K. Swallow and M. P. Mcgonagle (2005), 'Context-Sensitive Benefit Transfer Using Stated Choice Models: Specification and Convergent Validity for Policy Analysis', Journal of Environmental Management 31(4), 477-499.

Johnson, K. and K. Button (1997), 'Benefit Transfers: Are They a Satisfactory Input to Benefit Cost Analysis? An Airport Noise Nuisance Case Study', Transport Research 2(4), 223-231.

Kirchhoff, S. (1998), 'Meta-Analysis vs. Benefit Function Transfer as Policy-Making Tools: A Comparison', Invited Paper presented at the Workshop on "Meta-Analysis and Benefit Transfer: State of the Art and Prospects" at the Tinbergen Institute, Amsterdam.

Kirchhoff, S., B. G. Colby and J. T. LaFrance (1997), 'Evaluating the Performance of Benefit Transfer: An Empirical Inquiry', Journal of Environmental Economics and Management 33, 75-93.

Kristofersson, D. and S. Navrud (2005), 'Validity Tests of Benefit Transfer - Are We Performing the Wrong Test?', Environmental and Resource Economics 30(3), 279-286.

Krupnick, A., K. Harrison, E. Nickell and M. Toman (1996), 'The Value of Health Benefits from Ambient Air Quality Improvements in Central and Eastern Europe: An Exercise in Benefit Transfer', Environmental and Resource Economics 7, 307-332.

Ministry of Justice (2003), 'The Gaps Between asking price and Transaction Price in Sales of retail shops'. Assessor Office, Division of Research and Data on Land, Israel, (in Hebrew).

Muthke, T. and K. Holm-Mueller (2004), 'National and International Benefit Transfer Testing with Rigorous Test Procedure', Environmental and Resource Economics 29(3), 323-336.

Navrud, S. (2001), 'Valuing Health Impacts from Air Pollution in Europe', Environmental and Resource Economics 20(4), 305-329. 


\section{EXPLORING BENEFIT TRANSFER}

ODPM (Office of Deputy Prime Minister) (2002), Valuing the External Benefits of Undeveloped Land: A Review of the Economic Literature. Website: http://www.odpm.gov.uk.

Oglethorpe, D., N. Hanley, S. Hussain and R. Sanderson (2000), 'Modeling the Transfer of the Socio-economic Benefits of Environmental Management', Environmental Modeling \& Software 15, 343-356.

Pearce, D. W. and A. Howarth (2000), Technical Report on Methodology: Cost Benefit Analysis and Policy Responses. Report 481505020 for RIVM, EFTEC, NTUA and IIASA, p. 72. Website: http://search.msn.com/preview.aspx?\&q=RIVM-Report +481505020.

Ready, R., S. Navrud, B. Day, R. Dubourg, F. Machado, S. Mourato, F. Spanninks and M. Rodriquez (2004), 'Benefit Transfer in Europe: How Reliable are Transfers between Countries?', Environmental \& Resource Economics 29(1), 67-82.

Rozan, A. (2004), 'Benefit Transfer: A Comparison of WTP for Air Quality between France and Germany', Environmental \& Resource Economics 29(3), 295-306.

Shechter M. (1995), 'Valuing the Environment', Chapter 3 in: Principles of Environmental and Resource Economics. A Guide for Students and Decision-makers, edited by H. Folmer and H.L. Gabel. Edward Elgar Pub.

Smith, V. K. and J. Huang (1995), 'Can Markets Value Air Quality? A Meta-Analysis of Hedonic Property Value Models', The Journal of Political Economy 103, 209-227. 